\title{
GARANTISMO E A REGULAÇÃO DOS PODERES: ALTERNATIVAS À PENA DE PRISÃO
}

\author{
Melina de Albuquerque Wilasco*1
}

Resumo: Trata-se de trabalho no qual se revisa importantes conceitos na obra de Luigi Ferrajoli a fim de verificar como o constitucionalismo garantista pode colaborar com o debate acerca da crise do sistema carcerário. O tema é de relevância no cenário brasileiro no qual o modelo adotado de encarceramento em massa mostra-se absolutamente ineficaz, o que corrobora a necessidade de reflexão sobre o tema. Conclui-se, preliminarmente, que a proposta de Ferrajoli parece ser exequível mesmo em países que adotam políticas neoliberais. Realiza-se revisão bibliográfica para verificar se o garantismo constitucional pode fornecer a base teórica necessária para reformas do sistema prisional.

Palavras-chave: garantismo penal; direitos fundamentais; prisão; neoliberalismo; penas alternativas.

\section{“WARRANTISM"AND STATE REGULATION: MASS INCARCERATION ALTERNATIVES}

\begin{abstract}
This essay reviews important concepts from Luigi Ferrajoli in order to verify how his theory of "warrantism" (garantismo penale) can collaborate with the debate about the penal system crises. This is a relevant subject in Brazilian scenario, where the adopted mass incarceration model is absolutely ineffective, and calls out for the need of considering other ways of responding to crime. Preliminarily, we concluded that Ferrajoli's proposal seems to be a real possibility for countries with neoliberal politics orientation. We tried to verify, through bibliographic review, if Ferrajoli's theory can provide the necessary theoretical basis for changes in penal system incarceration.
\end{abstract}

\footnotetext{
1 * Mestranda em Direito e Sociedade na Universidade La Salle (Canoas/RS), Graduada em Ciências Jurídicas e Sociais na Universidade Federal do Rio Grande do Sul (UFRGS), Advogada Criminalista.
} 
Key words: penal "warrantism"; fundamental rights; incarceration; neoliberalism; alternative sentencing.

\section{Introdução}

Trata-se de trabalho no qual se analisam importantes conceitos na obra de Luigi Ferrajoli a fim de verificar como o constitucionalismo garantista proposto pelo autor italiano pode colaborar com o debate acerca da crise do sistema carcerário nos atuais tempos de neoliberalismo. Nesse sentido, é realizada revisão dos conceitos de direitos fundamentais e do constitucionalismo garantista.

Inicia-se a reflexão a partir da retomada dos conceitos sobre direitos fundamentais dentro do garantismo proposto por Luigi Ferrajoli. Em um segundo momento, discorre-se sobre a importância do garantismo penal e da regulação do poder nos tempos atuais. Passa-se, então, a examinar, de forma breve, a crise do constitucionalismo garantista.

Por fim, em resposta à crise do sistema penal, apresenta-se algumas propostas de alternativas à pena privativa de liberdade. Dessa forma, a partir de revisão bibliográfica de duas obras de Luigi Ferrajoli, pretende-se aprofundar o debate acerca das possíveis alternativas ao encarceramento.

\section{Direitos fundamentais na teoria garantista}

Atualmente, vivenciamos uma série de retrocessos ao redor do mundo, incentivados pela ideologia neoliberal que domina os países ocidentais. Nesse sentido, sobretudo em campos como o direito penal - alvo recorrente de conservadorismos e discursos populistas - figura-se mais que necessária a preservação das garantias já conquistadas. Sob esta ótica, o garantismo defendido por Luigi Ferrajoli parece conter importantes elementos para a reflexão e para a prática penal nos tempos atuais.

Ao responder à pergunta quais são os direitos fundamentais?, Ferrajoli propõe três respostas distintas. A primeira explicação, fornecida pela teoria do direito, diz que no plano teórico-jurídico a melhor definição de direitos fundamentais é aquela que identifica como fundamentais o direito que está adstrito universalmente a todos enquanto pessoas, sendo, 
portanto, indisponível e inalienável. Tal resposta, embora não exemplifique quais são os direitos fundamentais, demonstra que, se queremos que direitos sejam considerados fundamentais, estes não devem estar disponíveis à política e ao mercado (FERRAJOLI, 2008, p. 42).

Já a segunda resposta é apresentada pelo direito positivo (dogmática constitucional e internacional) e nos diz que os direitos fundamentais são, no plano nacional, aqueles universais e indisponíveis estabelecidos pelos respectivos ordenamentos dos países, e, no âmbito internacional, são aos direitos universais e indisponíveis estabelecidos na Declaração Universal De Direitos Humanos (FERRAJOLI, 2008, p. 42-43).

Por fim, Ferrajoli apresenta uma terceira resposta, oferecida pela filosofia política e defendida pelo autor nesta obra. A partir desta perspectiva, Ferrajoli busca definir que direitos devem ser garantidos como fundamentais, a partir de três critérios políticos e éticos (FERRAJOLI, 2008, p. 43).

O primeiro critério é o nexo entre direitos humanos e paz instituído na Declaração Universal Dos Direitos Humanos. Devem ser garantidos os direitos vitais necessários à manutenção da paz, ou seja: direito à vida, à integridade pessoal, direitos civis e políticos e direito à liberdade, direitos sociais (FERRAJOLI, 2008, p. 43). O autor aponta que, embora a paz social seja mais sólida e os conflitos sociais menos violentos à medida que as garantias aos direitos de vida são mais efetivos e estendidos, o preâmbulo da Declaração Universal Dos Direitos Humanos não é respeitado em diversos países. Com efeito, além de muitos Estados ainda viverem em situação de guerra, a existência de fronteiras impede que as pessoas procurem seu direito à autodeterminação. Assim, a questão migratória e a problemática da autodeterminação são desafios da atualidade (FERRAJOLI, 2008, pp. 44-48).

$\mathrm{O}$ segundo critério é o nexo entre direitos e igualdade. Igualdade, aqui, significa igualdade nos direitos de liberdade, garantindo igual valor a todas pessoas e suas diferenças (nacionalidade, sexo, idioma, religião, opiniões políticas). Envolve, também, direitos sociais para garantir a redução das desigualdades econômicas e sociais (FERRAJOLI, 2008, p. 43). Para Ferrajoli, embora os países Europeus não possuam uma "unidade" entre si, capaz de unilos enquanto um Estado único, tampouco houve tal homogeneidade antes da criação dos Estados-nações. Assim sendo, os Estados modernos foram uma "invenção do século XIX", de forma que seria possível haver uma construção global de um sentido de pertencimento ao gênero humano. Tal construção de identidade coletiva dependeria, segundo o autor, da garantia dos direitos fundamentais (FERRAJOLI, 2008, p. 49-50). 
O terceiro e último critério é o papel dos direitos fundamentais como lei do mais fraco. Debruçar-se-á mais detalhadamente sobre ele, uma vez que se trata de importante critério no âmbito do direito criminal, pois se inexistissem os direitos fundamentais, valeria a lei do mais forte (física, política e socialmente) (FERRAJOLI, 2008, p. 43-44). Consoante o autor, podese afirmar que, historicamente, os direitos fundamentais em todas as constituições são resultados de lutas ou revoluções que romperam com a "normalidade" e "naturalidade" de alguma opressão ou discriminação. Esses direitos foram conquistados enquanto limitação dos poderes dos mais fortes (e defesa dos direitos dos mais fracos) em cada situação (FERRAJOLI, 2008, p. 51-52). Nas palavras de Ferrajoli,

No ha sido casualidad que los derechos humanos, y con ellos cada progreso de la igualdad, hayan nacido siempre al desvelarse una violación de la persona que se ha convertido en intolerable (FERRAJOLI, 2008, p. 52).

Nesse sentido, Ferrajoli assevera que a validade dos direitos fundamentais não depende de um certo grau de consenso social (FERRAJOLI, 2008, pp. 53-54). Chega-se no ponto nevrálgico que aproxima a teoria do autor italiano aos atuais desafios do direito criminal na América Latina. Atualmente, observamos um momento histórico delicado, em que a polarização política e o avanço da ideologia neoliberal parecem pôr em xeque direitos que, anos atrás, considerávamos indiscutíveis.

Parte-se, assim, da conclusão apresentada por Ferrajoli de que é empiricamente falsa a tese de que as normas sobre direitos fundamentais pressupõem sua aceitação moral. Com efeito, o primeiro direito à liberdade reconhecido foi em relação à liberdade religiosa. Naquela época, passou-se a aceitar o que antes era considerado heresia; porém, não se pode dizer que todas as pessoas (ou mesmo a maioria) concordavam com esse direito. Para Ferrajoli, a ideia de que todos devem compartilhar os valores contidos nos direitos fundamentais é uma tese axiológica que não compreende a doutrina liberal do Estado de direito (FERRAJOLI, 2008, p. 54).

Verifica-se, inicialmente, uma confusão entre direito e moral. A teoria garantista do Estado constitucional de direito, justamente por se basear na separação entre direito e moral, não requer a adesão aos valores ético-políticos que estão juridicamente incorporados à Constituição. A adesão a valores não é imposta, sendo, inclusive, proibido impor valores aos cidadãos. Assim, a razão pela qual as pessoas aderem à ética que subjaz ao Estado constitucional é justamente o fato de que não se requer nenhuma adesão (FERRAJOLI, 2008, p. 54). 
Além disso, existe também uma confusão entre convenção jurídica (ponto de vista interno) e suas condições de efetividade (ponto de vista sociológico externo). De fato, a formação de um "sentido comum cívico e moral" interessa à sociologia, mas não pode ser pretendido pela convenção jurídica. $\mathrm{O}$ direito não pode impor uma crença ideológica. (FERRAJOLI, 2008, p. 55).

Por fim, também se confundem o paradigma do Estado de direito e da democracia política. Não é verdade que uma norma só é legítima se apoiada pela maioria. Ferrajoli sustenta que sempre que queremos tutelar um direito fundamental, o subtraímos da esfera política, isto é, retiramos a disponibilidade de decisões sobre esse direito das mãos do mercado ou da maioria. Tutelar direitos fundamentais significa, portanto, torná-los invioláveis, indisponíveis e inalienáveis de forma que nenhuma maioria, nem a unanimidade, podem decidir abolir ou reduzir esse direito protegido. Não se pode confundir, adverte Ferrajoli, "democracia” com "a vontade da maioria" (FERRAJOLI, 2008, p. 56).

Verifica-se, portanto, a importância dos ensinamentos de Ferrajoli nos dias atuais, vez que sua concepção de direitos fundamentais permite que sejam protegidos de uma eventual maioria que lhes queira reduzir ou abolir.

\section{Garantismo e direito penal}

O termo "garantia", consoante Ferrajoli, é uma expressão jurídica utilizada para designar "qualquer técnica normativa de tutela de um direito subjetivo" (FERRAJOLI, 2008, p. 60, tradução nossa). Originalmente, entretanto, o termo possuía sentido mais restrito, sobretudo para os civilistas, referindo-se ao cumprimento de obrigações do direito patrimonial (FERRAJOLI, 2008, p. 60).

O termo foi ampliado a partir da criação do neologismo "garantismo" expressando, hoje, a tutela de direitos fundamentais, sobretudo no campo penal. A expressão "garantismo penal", consoante Ferrajoli, surgiu na cultura jurídica italiana de esquerda a partir da segunda metade dos anos 70, em resposta à legislação e jurisprudência da época que reduziram garantias processuais. O garantismo é, portanto, associado ao pensamento penal liberal (tradição clássica) e relaciona-se com a exigência de tutela do direito à vida, à integridade física e à liberdade das pessoas frente ao poder punitivo estatal (FERRAJOLI, 2008, p. 61). 
O conceito de garantismo defendido por Ferrajoli é, de fato, bastante estendido, de forma que, para o autor, existem diferentes tipos de garantirmos, a depender dos direitos que se pretende proteger. Para fins desse trabalho, todavia, importa o garantismo penal, o qual tutela o direito à liberdade frente a arbitrariedades policiais ou judiciais. Nesse sentido, concorda-se com Ferrajoli de que devemos pensar o garantismo enquanto oposição à ideia ilusória de que os direitos subjetivos do "mais fraco" seriam automaticamente respeitados e atendidos (FERRAJOLI, 2008, p. 62). Garantismo, portanto, significa

precisamente a tutela daqueles valores ou direitos fundamentais, cuja satisfação, mesmo contra o interesse da maioria, constitui o objetivo justificante do direito penal, vale dizer, a imunidade dos cidadãos contra a arbitrariedade das proibições e das punições, a defesa dos fracos mediante regras do jogo iguais para todos, a dignidade da pessoa do imputado, e, consequentemente, a garantia da sua liberdade, inclusive por meio do respeito à sua verdade (FERRAJOLI, 2002, p. 271).

Tal concepção ampliada de garantismo, portanto, é de extrema importância, pois nos permite impor limites àqueles poderes que, hodiernamente, disseminam valores neoliberais em oposição a qualquer tipo de limite ou controle.

Sob esse ponto de vista que trata da importância do garantismo em nossas democracias, importa referir a relação entre as histórias do garantismo e do constitucionalismo. Consoante Ferrajoli, embora as garantias constituam um sistema de proibições e obrigações, sua capacidade vinculante aos poderes superiores depende de seu rígido fundamento positivo nas normas constitucionais. Assim sendo, antes da invenção das constituições rígidas, as constituições não eram consideradas hierarquicamente superiores às leis ordinárias e podiam ser alteradas para reduzir ou suprimir direitos sem que isso configurasse qualquer ilegalidade (FERRAJOLI, 2008, p. 65).

A partir das constituições rígidas, as constituições e os direitos fundamentais passam a ser considerados "pactos sociais" escritos que definem a esfera que nenhuma maioria pode decidir: limites e proibições da garantia ao direito à liberdade e os vínculos e obrigações da garantia aos direitos sociais (FERRAJOLI, 2008, p. 62). Assevera Ferrajoli:

Trata-se de uma profunda transformação do paradigma original do positivismo jurídico, que culmina com o princípio, característico do direito do Estado, da sujeição à lei de todo poder, incluindo, portanto, o próprio poder legislativo. Graças a essa transformação, modifica-se a natureza da validade das leis, que deixa de coincidir com sua mera existência determinada pelo simples respeito à forma e procedimentos 
estabelecidos pelas normas formais sobre sua produção, e que exige, ademais, a coerência de seus significados com os princípios constitucionais. Em segundo lugar, modifica-se a natureza da jurisdição e da ciência jurídica as quais não mais correspondem unicamente à aplicação e ao conhecimento de uma norma legal qualquer, mas que assumem também um papel crítico de sua invalidade sempre que possível (FERRAJOLI, 2008, p. 66, tradução nossa).

Para Ferrajoli, portanto, o garantismo constitucional introduziu nas democracias ocidentais uma dimensão substancial que modifica o antigo paradigma do Estado. Assim, no Estado democrático de direito a legitimidade, tanto política quanto jurídica, do poder não está condicionada apenas às regras formais, mas também a seu conteúdo.

\section{A regulação do poder em tempos de neoliberalismo}

Sabe-se que a modernidade capitalista possui sua máxima expressão através do Estado liberal que, entre outras funções, assumiu o monopólio da produção do direito (SANTOS, 2003, p. 4). Ao mesmo tempo, o sociólogo Boaventura de Sousa Santos identifica a mitigação das possibilidades reais de emancipação social, motivo pelo qual considera que a principal tarefa jurídico-científica atual é "reinventar o direito para lá do modelo liberal", de modo a combater a agenda conservadora (SANTOS, 2003, p. 8) cada vez mais presente em nosso dia a dia. Em sentido semelhante, Ferrajoli entende que:

"A história do Estado de direito, do constitucionalismo democrático e dos direitos humanos pode ser lida como a história de uma grande luta contra o absolutismo do poder, quer dizer, contra uma liberdade selvagem" (FERRAJOLI, 2008, p. 58, tradução nossa).

Verifica-se, de fato, que essa "grande luta" inicialmente combateu o poder público feudal e, mais recentemente, travou uma batalha contra os poderes econômicos e empresariais. Esta última batalha ocorreu através da regulamentação sobre o direito do trabalho, dos limites impostos ao setor empresarial, e das reformas legislativas no direito de família (equiparação entre homem e mulher, reconhecimento da união homoafetiva, etc). Em todos esses casos, os direitos fundamentais conquistados se configuram como "lei do mais fraco" e como verdadeiros e necessários limites a esses poderes antes absolutos (FERRAJOLI, 2008, p. 58).

Tanto Santos quanto Ferrajoli, entretanto, consideram que estamos vivendo, atualmente, um momento de crise global. Ferrajoli diz que se trata de crise do estado de bem-estar social, 
das garantias ao direito do trabalho e da ausência de regras do atual capitalismo globalizado (FERRAJOLI, 2008, p. 58-59). Santos, por seu turno, entende que desde a década de 70 os países centrais vivem uma crise do Estado-Providência, e que o capitalismo se organizou de tal forma que hoje domina "todos os aspectos da vida social", não sendo apenas um "modo de produção'. O sociólogo português diz que as duas promessas do segundo período do capitalismo (distribuição mais justa de riquezas e sistema político estável e democrático) "não tiveram continuidade e estão, aliás, a deteriorar-se". Como exemplo, cita o aumento alarmante da pobreza, aparecimento de terceiros mundos, diminuição de políticas sociais e o novo populismo (SANTOS, 2002, p. 153-154).

Ambos, portanto, concordam que a globalização da economia sem a existência de regras produziu um crescimento exponencial das desigualdades sociais que vai desde a concentração da riqueza à expansão da fome e da exploração. Hoje, os bilionários concentram mais de 60\% da riqueza mundial ${ }^{2}$. Tal desigualdade vem sendo legitimada pelas ideologias neoliberais, que pregam que a autonomia empresarial não é um "poder", e sim uma "liberdade" e que o mercado não precisa de regras nem de limites.

Segundo Ferrajoli, essas ideias neoliberais são contrárias à lógica do Estado de direito e do constitucionalismo e, ainda assim, esse ideal é reproduzido sistematicamente em todo o mundo. Para ele, estamos vivendo uma crise do constitucionalismo e, em sentido mais amplo, uma crise da legalidade e dos direitos humanos - tanto dentro dos nossos ordenamentos jurídicos quanto na política internacional (FERRAJOLI, 2008, p. 58-59). Nesse sentido, a concepção ampla de direitos fundamentais apresentada por Ferrajoli compreende importantes elementos na atualidade.

\section{A crise do garantismo constitucional}

Com efeito, o garantismo constitucional produziu importantes resultados nas democracias ocidentais. Todavia, Ferrajoli adverte que o paradigma garantista e constitucional trata-se de um paradigma teórico e normativo, ou seja, certamente não-realizável de maneira perfeita. De fato, é possível que algumas garantias a direitos fundamentais não estejam

\footnotetext{
${ }^{2}$ https://www.redebrasilatual.com.br/economia/2020/01/oxfam-bilionarios-tem-mais-riqueza-que-60da-populacao-

mundial/\#: :text=Brasil\%20de\%20Fato\%20\%E2\%80\%93\%200s\%202.153,renda\%20chegou\%20a\%2 On\%C3\%ADvel\%20recorde.
} 
expressamente estabelecidas na Constituição de determinado Estado. É possível, também, que as garantias e direitos fundamentais sejam constitucionalmente estabelecidos, mas violados pelo próprio poder público. Isto explica, segundo o autor, porque o paradigma garantista sempre será um paradigma em desenvolvimento, mesmo que esteja expresso na constituição (FERRAJOLI, 2008, p. 67).

No atual contexto em que vivemos, entretanto, não faltam tentativas de deslegitimar e de enfraquecer as garantias constitucionais e os direitos fundamentais estabelecidos, de forma que precisamos refutar tais argumentos.

Há quem sustente, por exemplo, que os direitos humanos estabelecidos nas declarações internacionais não são vinculantes, pois carecem de garantias. $\mathrm{O}$ argumento seria de que um direito não-garantido não seria, na verdade, um direito, e sim, um direito formalmente reconhecido, porém não-judicializável. Tal abordagem, consoante Ferrajoli, confunde direitos com suas garantias. Essa confusão, além de anular boa parte das conquistas mais importantes do constitucionalismo do século XX, contradiz a tese kelseniana, segundo a qual a existência ou inexistência das normas que disponham sobre obrigações, proibições ou direitos subjetivos não se deduz da existência ou inexistência de outras normas, mas são introduzidas no ordenamento jurídico pelos correspondentes atos de produção legislativa. É, portanto, perfeitamente possível que um ordenamento jurídico que prevê um direito subjetivo não possua (ainda) uma norma a ele correspondente, porém isto não invalida a garantia ao direito subjetivo (FERRAJOLI, 2008, p. 71-72).

Entretanto, ao contrário do que dizem os defensores de tal tese, a ausência de norma não autoriza dizer que os direitos a ela correspondentes não existam. Muito pelo contrário: impõe dizer que o reconhecimento da ausência de tais normas é um descumprimento que constitui uma lacuna indevida no ordenamento jurídico. A principal consequência desta distinção entre direitos e garantias, imposta pelo direito moderno positivo, assevera Ferrajoli, é de que o nexo entre direitos e garantias não é um nexo empírico, e sim um nexo normativo (FERRAJOLI, 2008, p. 74).

O reconhecimento de que a relação entre direitos e garantias se trata de um nexo normativo (e não empírico) é importante no contexto em que vivemos. A ideologia liberal, como se sabe, espalhou-se por todo o ocidente, de maneira que se verifica um verdadeiro retrocesso, pois além de não serem criadas novas formas de limitação aos poderes econômicos, 
muitos dos limites antes impostos foram derrubados pelo ideal liberal (FERRAJOLI, 2008, p. 74).

Verifica-se, portanto, que tal crise do garantismo constitucional nos convida a defender as garantias e os direitos já conquistados (e hoje ameaçados). Para tanto, parece fundamental compreender tais direitos e garantias enquanto expectativas a longo prazo, destinadas, provavelmente, a não serem totalmente satisfeitas. Ao mesmo tempo, é necessário que se busque não aumentar a abissal diferença entre norma e realidade, entre direitos proclamados e direitos efetivados (FERRAJOLI, 2008, p. 75).

\section{A crise do sistema penal}

Se o garantismo constitucional encontra-se em crise, não é diferente em relação ao garantismo penal. No campo criminal, pode-se falar em carência ou inefetividade das garantias constitucionalmente estabelecidas. As garantias penais e processuais penais são, essencialmente, garantias negativas, isto é, designadas para limitar o poder punitivo em defesa das liberdades individuais. Em aproximação ao projeto de "direito penal mínimo", tais garantias pressupõem um sistema penal cuja intervenção punitiva seja submetida a limites rígidos, impostos em defesa dos direitos da pessoa acusada (FERRAJOLI, 2008, p. 67).

Em termos mais específicos, Ferrajoli diferencia as garantias penais substanciais das garantias penais processuais. Como exemplo de garantia penal substancial, estão: princípio da legalidade ou da taxatividade estrita; e princípio da ilicitude, materialidade e culpabilidade. Já os limites processuais penais correspondem ao princípio do contraditório e da ampla defesa; à paridade de armas; à separação rígida entre juiz e acusação; à presunção de inocência; ao ônus probatório do Ministério Público; à oralidade e à publicidade do julgamento; à independência interna e externa do magistrado; e ao princípio do juiz natural (FERRAJOLI, 2008, p. 67-68).

Infelizmente, entretanto, Ferrajoli reconhece que (mesmo na Itália) tal modelo garantista não é aplicado e que o sistema penal italiano possui "amplos espaços de discricionariedade gerados pelo déficit de garantias do nosso sistema judicial" (FERRAJOLI, 2008, p. 70).

Em que pese cada país possua sua própria história, verifica-se verdadeira semelhança entre os exemplos elencados por Ferrajoli em relação ao direito penal italiano e a realidade que vivemos no Brasil. Segundo Ferrajoli, a Itália sofreu com um considerável aumento de tipos 
penais, os quais estão cada vez mais indeterminados - e, portanto, sujeitos a maiores arbitrariedades do poder punitivo. O sistema penal italiano sofreu, ainda, flexibilização das garantias processuais, reforçando enormemente o poder acusatório em prejuízo da defesa e da instrução probatória frente ao julgamento (FERRAJOLI, 2008, p. 70).

Ferrajoli explica que tais retrocessos ocasionaram, na Itália, conflitos entre poderes, divisão da opinião pública italiana e envenenamento do debate sobre a justiça penal. Essa quebra da legalidade, adverte o autor, desqualifica todo o sistema penal (sua certeza, sua cognoscibilidade e sua eficácia), ampliando os espaços de arbitrariedade e comprometendo todo o processo penal (FERRAJOLI, 2008, p. 70).

\section{A crise do sistema de penas e as alternativas do direito penal mínimo}

Em outra obra, Ferrajoli explica que também o sistema de penas está em profunda crise, com a qual contribuíram diversos fatores, tais como: aumento da prisão provisória; espetacularização midiática de processos penais; inflação do direito penal; mudanças nas formas de criminalidade (crime organizado e "microdelinquência difusa"); diminuição delitos contra a pessoa e aumento dos delitos contra a propriedade; progressivo desenvolvimento de ideais contrários à prisão perpétua e outras penas cruéis (FERRAJOLI, 2002, p. 329-330).

Todas essas mudanças, conforme observa Ferrajoli, tornam "anacrônicos" ou "inadequados" tanto o sistema de previsão de delitos quanto o sistema de cumprimento de penas. É neste ponto que Ferrajoli sustenta importante argumento: as penas existentes em nossos ordenamentos não satisfazem "os fins que justificam o direito penal : umas, por serem demasiado aflitivas, outras, por serem demasiado pouco aflitivas, e tanto umas quanto outras, por serem ineficazes ou, pior ainda, contraproducentes" (FERRAJOLI, 2002, p. 330).

Nesse sentido, Ferrajoli defende que, embora a pena privativa de liberdade seja cada vez mais criticada e considerada "inócua" e "irracional", as penas chamadas alternativas parecem corroborar a lógica carcerocêntrica, sendo, muitas vezes, acumuladas com a pena

\footnotetext{
${ }^{3}$ Existem outros autores que questionam a própria legitimidade do direito penal, pois seria uma apropriação indevida do Estado para resolver conflitos entre cidadãos. Nesse sentido, Daniel Achutti assevera que "o processo penal não apresenta condições de responder adequadamente aos conflitos criminais contemporâneos, pois parte da premissa equivocada: baseado em teorias contratuais, considera que o Estado é o principal ofendido com a prática de delitos, e, portanto, deve ser o responsável pela iniciativa de punir o infrator" (ACHUTTI, 2016, p. 39). Todavia, para fins deste artigo em específico, tal discussão referente à legitimidade do direito penal não será debatida, adotando-se apenas a teoria garantista de Luigi Ferrajoli.
} 
privativa de liberdade. A sobreposição de penas (carcerária e alternativa), somada ao fato de que tais penas alternativas muitas vezes não respeitam garantias processuais penais, possibilitam um espaço de discricionariedade judicial, maculando, assim, o que poderiam ser as "principais inovações deste século em matéria de técnicas sancionadoras" (FERRAJOLI, 2002, p. 330).

Em sentido semelhante - embora deduza conclusões distintas das de Ferrajoli - Angela Davis questiona por que as prisões ainda são consideradas inevitáveis em nossa sociedade, demonstrando que, ao mesmo tempo que parece ser impossível imaginar uma vida sem prisões, as pessoas relutam a refletir sobre os estabelecimentos prisionais e o que ocorre em seu interior. Nas palavras da autora, "consideramos as prisões algo natural, mas com frequência temos medo de enfrentar as realidades que elas produzem". Segundo a Davis, é comum que a prisão seja considerada um local onde os outros, os criminosos, são colocados, um verdadeiro "buraco negro" onde "são depositados os detritos do capitalismo contemporâneo" (DAVIS, 2018, p. 16-17).

Assim, com o objetivo de resolver as atuais inconsistências no cumprimento das penas, Ferrajoli sugere algumas mudanças relacionadas à pena privativa de liberdade. A curto e médio prazo, o autor defende a diminuição do uso do cárcere e a diminuição do limite máximo de pena, bem como a extinção da prisão perpétua; a longo prazo, a abolição desse tipo de sanção. Assevera, para tanto, que a pena privativa de liberdade não satisfaz nenhuma de suas "razões", pois não previne delitos (podendo, inclusive, virar verdadeira escola do crime organizado); tampouco previne a vingança privada (sobretudo em processos que viram midiáticos). Argumenta que o cárcere, além da privação à liberdade, configura verdadeira pena aflitiva, a qual distingue-se dos antigos castigos corporais apenas pois as violências físicas e psicológicas encontram-se dilatadas ao longo do tempo de cumprimento da pena (FERRAJOLI, 2002, p. 330-331). Nas palavras do autor:

A prisão é, portanto, uma instituição ao mesmo tempo antiliberal, desigual, atípica, extralegal e extrajudicial, ao menos em parte, lesiva para a dignidade das pessoas, penosa e inutilmente aflitiva. Por isso resulta tão justificada a superação ou, ao menos, uma drástica redução da duração, tanto mínima quanto máxima, da pena privativa de liberdade, instituição cada vez mais carente de sentido, que produz um custo de sofrimento não compensados por apreciáveis vantagens para quem quer que seja (FERRAJOLI, 2002, p. 331). 
Nesse contexto, Ferrajoli defende que, para crimes mais graves, a pena privativa de liberdade tenha duração máxima de dez anos, e, para crimes mais leves, a sanção carcerária seja substituída por medidas alternativas. Tais medidas alternativas, entretanto, deveriam de fato substituir (e não se acumular) com a pena privativa de liberdade. Assim, Ferrajoli sustenta que os ordenamentos jurídicos deveriam prever as penas alternativas (prisão domiciliar, limitação de final de semana, semiliberdade, monitoramento eletrônico, etc) como penas principais (autônomas) para crimes menos graves, respeitando-se o princípio da anterioridade, da taxatividade e da não-discricionariedade (FERRAJOLI, 2002, p 366-337).

Trata-se, sem dúvida, de interessante proposta, eis que se mostra exequível dentro dos ordenamentos jurídicos ocidentais da atualidade. Com efeito, tal proposta pode ser factível mesmo nos países que sofrem com a onda neoliberal, vez que se trata de reforma do sistema penal existente, lastreada e baseada em princípios liberais. Sob outro aspecto, a proposta de Ferrajoli é interessante pois prevê às penas uma "graduação proporcional e sua ponderação equitativa, de acordo com a gravidade dos delitos" (FERRAJOLI, 2002, p 337).

Interessante notar, ainda, que o argumento utilizado por Ferrajoli corrobora toda a tese supracitada referente às garantias penais e direitos fundamentais dentro do constitucionalismo. Com efeito, o autor italiano relembra a tese de Cesare Beccaria ao asseverar que a liberdade, enquanto direito personalíssimo, é inalienável e indisponível, de forma que deve ser proibida a sua privação total; por outro lado, os demais direitos são disponíveis e admitiram, assim, variadas restrições ou privações (FERRAJOLI, 2002, p 337). Em suas palavras:

Talvez a verdadeira utopia de hoje não seja a alternativa ao direito penal, mas, sim, o próprio direito penal e as suas garantias, não o abolicionismo, mas o garantismo, mesmo se inevitavelmente parcial e imperfeito (FERRAJOLI, 2002, p 276).

A tese de garantismo constitucional aplicada ao direito penal de Luigi Ferrajoli, portanto, nos fornece importantes elementos - de cunho jurídico e filosófico - ao mesmo tempo que está lastreada em conceitos liberais e, dessa forma, conciliáveis, em alguma medida, com os atuais ideais do neoliberalismo. Trata-se, assim, de promissora proposta no contexto de países ocidentais.

\section{Conclusões preliminares}


De forma preliminar, conclui-se que o campo do direito penal pode utilizar-se da teoria garantista de Luigi Ferrajoli, sobretudo a interpretação filosófica e política do autor apontando que devemos pensar o garantismo enquanto oposição à ideia ilusória de que os direitos subjetivos do "mais fraco" seriam automaticamente respeitados. Com efeito, tais ensinamentos possuem muita relevância nos dias atuais de hegemonia neoliberal, vez que tal concepção de direitos fundamentais permite que estes sejam protegidos de uma eventual maioria que lhes queira reduzir ou abolir.

Com o objetivo de salvaguardar o direito à liberdade, a teoria de Ferrajoli nos permite afirmar que a legitimidade do poder Estatal não está condicionada apenas às regras formais, mas também a seu conteúdo. Dessa forma, a defesa do garantismo constitucional nas democracias ocidentais mostra-se um importante instrumento de controle e regulação do poder punitivo - sobretudo em tempos de populismo penal.

Além da crise mundial com o avanço da ideologia neoliberal, os países ocidentais vivem, ainda, a crise do sistema penal e do sistema punitivo. Verifica-se que tanto o rol de delitos previstos quanto o sistema de cumprimento de penas e o modelo de encarceramento em massa são absolutamente ineficazes. Nesse sentido, é urgente que pensemos em alternativas a esta falida lógica carcerocêntrica.

Em uma perspectiva jurídica e filosófica lastreada no direito liberal, Ferrajoli defende profundas mudanças no sistema de penas, de forma a diminuir drasticamente a utilização da pena privativa de liberdade, a qual seria aplicada apenas em crimes mais graves. $\mathrm{Na}$ linha de direito penal mínimo garantista defendida pelo autor italiano, o cárcere teria uma duração máxima, e a maioria dos crimes mais leves seria punida apenas por medidas alternativas.

Assim sendo, parece que a tese de garantismo constitucional aplicada ao direito penal de Luigi Ferrajoli pode nos fornecer interessantes alternativas à pena de prisão. Ademais, a argumentação utilizada pelo autor está lastreada em conceitos liberais e, dessa forma, tal teoria mostra-se conciliável, em alguma medida, com os atuais ideais do neoliberalismo. Conclui-se, portanto, tratar-se de proposta crível e exequível dentro do contexto atual, motivo pelo qual mostra-se relevante a presente análise.

\section{Bibliografia:}


ACHUTTI, Daniel. Justiça Restaurativa e Abolicionismo Penal: contribuições para um novo modelo de administração de conflitos no Brasil. São Paulo: Editora Saraiva, $2^{\mathrm{a}}$ edição, 2016.

DAVIS, Angela. Estarão as Prisões Obsoletas? Rio de Janeiro: Difel, 2018.

FERRAJOLI, Luigi. Direito e Razão: Teoria do Garantismo Penal. São Paulo: Editora Revista do Tribunais, 2002.

FERRAJOLI, Luigi. Democracia y garantismo. Madrid: Trotta, 2008.

SANTOS, Boaventura de Sousa. A crítica da razão indolente: contra o desperdício da experiência. Para um novo senso comum. A ciência, o direito e a política na transição paradigmática. Volume 1, 4ª edição, São Paulo, Editora Cortez, 2002.

SANTOS, Boaventura de Sousa. Poderá o direito ser emancipatório? Revista Crítica de Ciências Sociais, Centro de Estudos Sociais da Universidade de Coimbra. Edição 65, p. 3-76, maio 2003. 